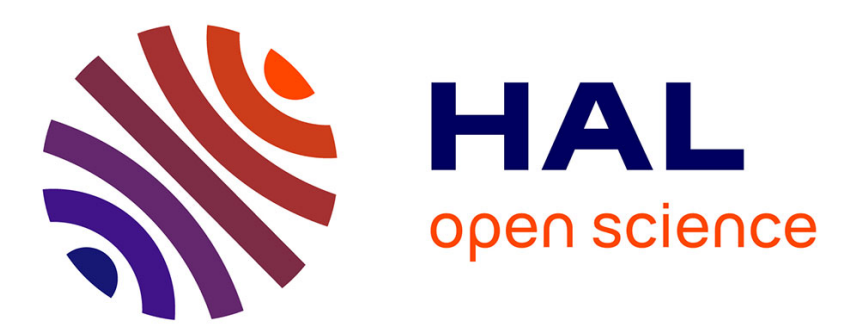

\title{
Synthesis of Polyacrylic/Silica Nanocomposite Latexes using Static Mixer
}

\author{
Gholamali Farzi, Elodie Bourgeat-Lami, Timothy Mckenna
}

\section{To cite this version:}

Gholamali Farzi, Elodie Bourgeat-Lami, Timothy Mckenna. Synthesis of Polyacrylic/Silica Nanocomposite Latexes using Static Mixer. Macromolecular Symposia, 2010, 289, pp.129-134. 10.1002/masy.200900015 . hal-00723802

\section{HAL Id: hal-00723802 https://hal.science/hal-00723802}

Submitted on 8 Oct 2021

HAL is a multi-disciplinary open access archive for the deposit and dissemination of scientific research documents, whether they are published or not. The documents may come from teaching and research institutions in France or abroad, or from public or private research centers.
L'archive ouverte pluridisciplinaire HAL, est destinée au dépôt et à la diffusion de documents scientifiques de niveau recherche, publiés ou non, émanant des établissements d'enseignement et de recherche français ou étrangers, des laboratoires publics ou privés. 


\title{
Synthesis of polyacrylic/silica nanocomposite latexes using static mixer
}

\author{
G.A.Farzi ${ }^{1}$, E. Bourgeat-Lami, T.F.L.McKenna ${ }^{2}$,
}

CCPP/CPE UMR 5265, 43 Bd du 11 Nov. 1918, BP 2077, 69616 Villeurbanne Cedex, France, e-mail: *tim.mckenna@ chee.queensu.ca

Summary. Static mixers (Sulzer Chemtech; SMX) were used to prepare silica/ MMAco-BA miniemulsions that were polymerized to produce nanocomposite latexes. Acceptable conditions for the formulation of polymerizable nanodroplets were found. and subsequently used to produce silica/poly(MMA-co-BA) nanocomposites by introducing silica-loaded monomers and preparation of silica-loaded miniemulsions. The droplet size distribution of the resulting miniemulsions was narrow enough that it could be successfully polymerized. It was found that the droplet size depends on the silica content and increases with increasing the silica concentration. It was also shown that there is a relationship between the droplet size and the viscosity of the dispersed phase. The majority of droplets were nucleated upon polymerization when less than $15 \%$ silica was used. However, when the silica content exceeded $15 \%$, the ratio of the number of particles in the final latex to the number of droplets $(\mathrm{Np} / \mathrm{Nd})$ increased to value much higher than 1 indicating the occurrence of homogeneous nucleation.

Keywords: silica, nanocomposite, miniemulsion, static mixer, droplet size, particle size.

\section{Introduction}

Emulsion polymerization is widely used as a means of making a numerous commercially important products, but does not always offer the necessary flexibility in terms of particle generation needed to produce a range of composite materials. Beginning in the 1970 's, researchers began to understand that if the monomer droplets were small enough, they could also capture free radicals and thus polymerize. ${ }^{1}$ This was the beginning of miniemulsion polymerization, which has now evolved as an alternative to conventional emulsion polymerization. The ingredients of a miniemulsion system are similar to a conventional system, with the addition of a hydrophobic agent. The main difference between conventional and

\footnotetext{
${ }^{1}$ Current address: Department of polymer engineering, Amirkabir University of Technology, Tehran, Iran

${ }^{2}$ Current address: Department of Chemical Engineering, Queen's University, Kingston, ON, Canada
} 
miniemulsion polymerization is the mechanism of particle creation. ${ }^{3-5}$ In commercial emulsion polymerization processes, micellar nucleation is the main method of particle formation. In contrast to a conventional system, monomer droplets are much smaller $(50-500 \mathrm{~nm})$, and are created by some type of intesive mixing process. If they are small enough, and if there are no micelles present in the reactor they will be the main locus of polymerization. In an ideal miniemulsion, we will obtain one polymer particle per initial droplet (i.e. $\mathrm{Np} / \mathrm{Nd}=1$ ). These droplets are stabilized by a two component system: the surfactant (similar to those used for convecntional emulsion polymerization) and the hydrophobe. ${ }^{2}$ The surfactant provides the steric and/or electrostatic stabilization, and the hydrophobic agent retards Ostwald ripening; that is to say the degradation of smaller droplets at the expense of larger droplets.

In miniemulsion polymerization, the droplets (which need to be small enough to capture free radicals at a significant rate) behave as individual reactors, and since they are formed by mechanical agitation this offers certain advantages over conventional emulsion processes in that oil soluble compounds can be directly integrated into the polymer particle "ab initio" to make hybrid or composite materials (or even be used as initiators to limit water-phase reactions).

As we mentioned above, miniemulsification necessarily involves an intensive mechanical agitation step. Ultrasound (US) is traditionally used on the lab scale, but its use is limited for industrial application. For this reason, the use of more industrially efficient homogenizers such as static mixers (SMs), high pressure homogenizers or rotor-stator (RS) mixers is desirable. There are many reports concerning the use of SM for mixing two immiscible fluids, but its use for a miniemulsification process has not been well investigated and understood.

Ouzineb et al..$^{6,7}$ and Farzi et al. ${ }^{8}$ studied the use of SM's for the miniemulsification of single monomer systems like styrene (ST), butyl methacrylate (BMA) and methylmectacrylate (MMA). They showed that it is possible to make stable miniemulsion droplets by SM. In the latter study, we showed that it is possible to homogenize MMA with an SM assembly and to polymerize the resulting nanodroplets. It was also found that higher flow rates and well-defined mixer geometries are needed to emulsify mixtures of MMA and BA. In the current work we will build on these results, first to identify acceptable conditions for the miniemulsification of a 50/50 wt\% mixture of MMA/BA. Subsequently a silica-loaded monomer was emulsified to create nanodroplets containing silica nanoparticles. These droplets were consequently polymerized using miniemulsion polymerization technique. 


\section{Experimental Details}

\section{Materials}

The aqueous silica suspension used in this study was graciously supplied by Clariant (France). The main characteristics of this suspension, referred to as GEN33 are shown in Table 1. The specific surface area of silica particles was determined from nitrogen adsorption isotherms using the Brunaeur, Emmett, Teller (BET) method. The diameter of the silica particles and polydispersity index (PI) were determined by DLS using a Malvern Autosizer.

Table 1 Characterization of supplied silica particles in water

\begin{tabular}{ll}
\hline & GEN 33 \\
\hline Specific surface area (Sspec, m2/g) & 50.5 \\
Particle diameter (DSiO2, nm) & 78 \\
Polydispersity index (PI) & 0.020 \\
Solid content (SC, \%) & 27 \\
Suspension pH & 9.57 \\
\hline
\end{tabular}

$\gamma$-methacryloxy propyl trimethoxysilane ( $\gamma$-MPS, Acros organics) was used as coupling agent through this work.

Absolute ethyl alcohol (99.8\%) and methyl alcohol (99.9\%) were obtained from Carlo Erba, and used as received. MMA and BA and Sodium dodecyl sulphate (SDS) were obtained from Acros and used as received.

\section{Miniemulsification procedure}

As mentioned before, it was shown in our previous work ${ }^{8}$ that it is possible to create stable miniemulsion of one single monomer like MMA using a set-up of $8 \mathrm{~mm}$ diameter SMX static mixer shown schematically in Figure 1. The SM set-up consisted of 7 elements of $0.7 \mathrm{~cm}$ (these were $8 \mathrm{~mm}$ elements machined down to $7 \mathrm{~mm}$ in order to fit in the tube) placed in a polytetrafluoroethylene (PTFE) housing. This housing was attached to a longer nylon tube with the same diameter, through which the liquid phase was recycled during homogenization. A pump with a theoretical pressure loss of 8.7 bar and maximum flowrate of $133 \mathrm{ml} / \mathrm{s}$ of emulsion was used to recirculate the fluid. 


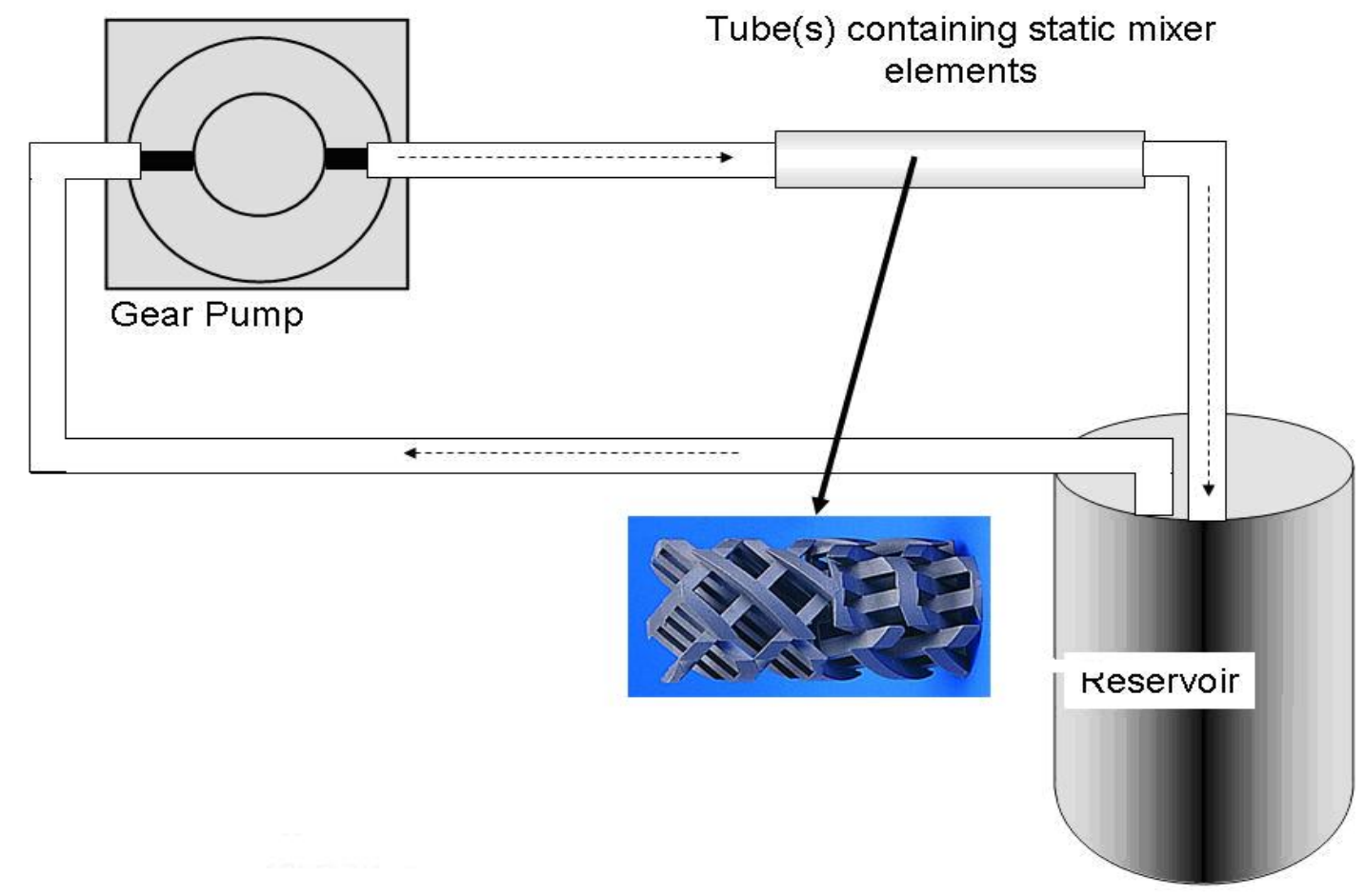

Figure 1. Static mixer homogenisation set-up.

\section{Results and discussions}

\section{Formation of mixed monomer droplets}

The objective of this initial section is to find acceptable conditions for the formation of nanodroplets and polymerization of a 50/50 MMA/BA mixture. For this purpose, the droplets need to be small enough so that they may successfully compete for free radicals and monomodal enough that they can be polymerized successfully. ${ }^{1,9}$. The mixed monomer system (MMA/BA 50/50 wt \%) was homogenized using the SMX mixing elements according to the recipe given in Table 2. The flow rate of the pump was varied from $114 \mathrm{ml} / \mathrm{s}$ to $133 \mathrm{ml} / \mathrm{s}$ and breakage of droplets was studied. Figure 2 shows the evolution of droplet diameter of miniemulsions as a function of recycle time for increasing flow rates. It can be seen from this figure that regardless of the flow rates, the droplet diameter decreases with increasing homogenization time and then reaches a plateau. As expected, Figure 2 also shows that smaller droplets are obtained at higher flow rates. 
Table 2 Miniemulsion recipe

\begin{tabular}{ccccc}
\hline Water & Monomer & Hydrophobic agent & Surfactant & Initiator \\
\hline $69.35 \mathrm{~g}$ & $28.1 \mathrm{~g}$ & $2 \mathrm{~g}(\mathrm{ODA})$ & $0.17 \mathrm{~g}$ TA, $0.26 \mathrm{~g}$ TN & $0.12 \mathrm{~g}$ APS \\
\hline
\end{tabular}

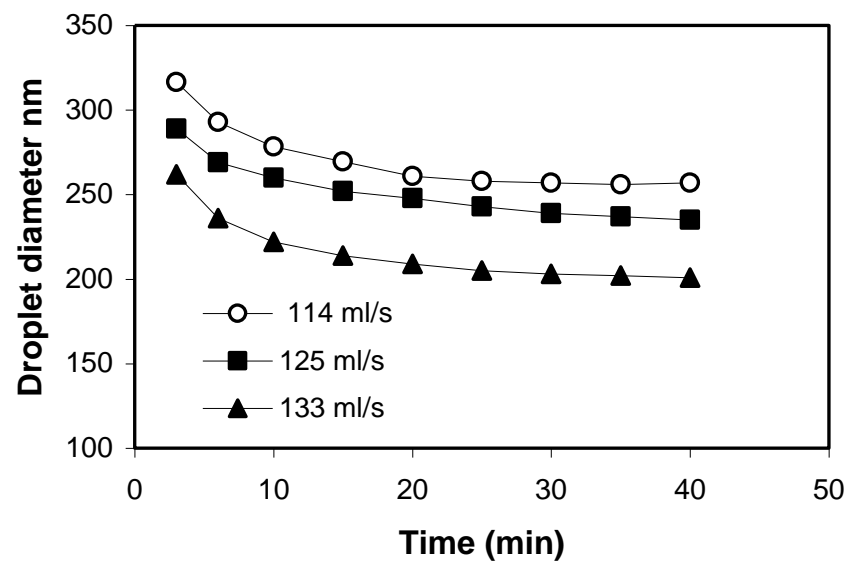

Figure 2. Evolution of droplet diameter as a function of recycle time.

The polydispersity indices (value reported by Malvern Software. A value of less than 0.1 is considered to be monodisperse) of miniemulsions thus created is shown in Figure 3. As can be seen, the polydispersity index of the miniemulsion created at higher flow rate is the smallest.

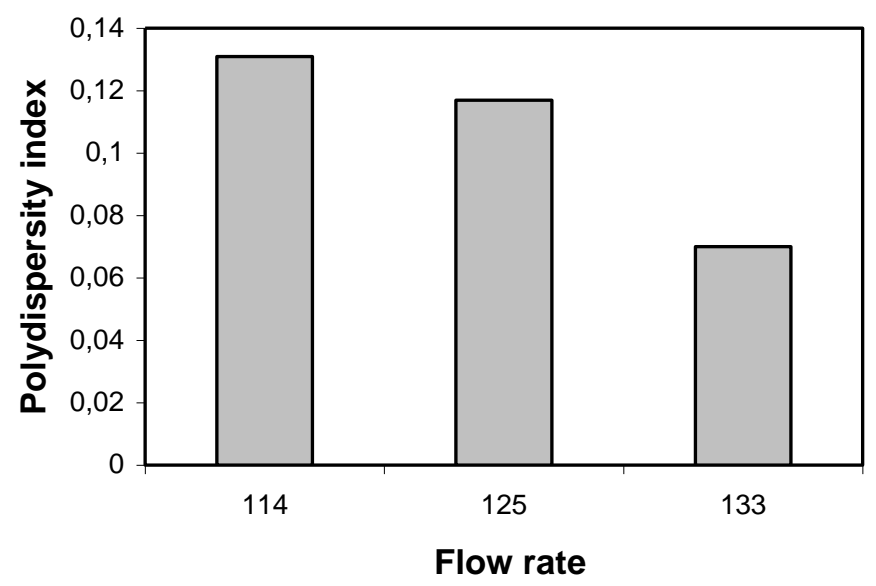

Figure 3. Polydispersity of miniemulsions after 30 minutes homogenization.

These dispersions were polymerized according to the recipe in Table 3 via a batch process in a cylindrical glass reactor $(150 \mathrm{ml})$ with a nitrogen inlet. Droplet diameters of miniemulsions after 30 minutes of homogenization, conversion of polymerization reaction after 
120 minutes, particle size and polydispersity index of latexes and also $\mathrm{N}_{\mathrm{p}} / \mathrm{N}_{\mathrm{d}}$ are given in Table 4 for different flow rates.

Table 3. Effect of flow rate on characteristics of samples

\begin{tabular}{cccccc}
\hline Flow rate & $\mathrm{D}_{\mathrm{d}}$ & Conversion & $\mathrm{D}_{\mathrm{p}}$ & $\mathrm{PI}$ & $\mathrm{N}_{\mathrm{p}} / \mathrm{N}_{\mathrm{d}}$ \\
\hline 114 & 257 & 0.95 & 181 & 0.082 & 2.39 \\
125 & 235 & 0.97 & 183 & 0.076 & 1.76 \\
133 & 201 & 0.96 & 189 & 0.056 & 1.11 \\
\hline
\end{tabular}

The highest flow rate gave the narrowest DSD, which in turn could be polymerized to yield a narrow PSD with $\mathrm{N}_{\mathrm{p}} / \mathrm{N}_{\mathrm{d}}$ closest to unity, indicating efficient nucleation of the nanodroplets. ${ }^{10}$ The best condition that we obtained corresponds to the flow rate of $133 \mathrm{ml} / \mathrm{s}$. Therefore, this condition was used in the following experiments.

\section{Droplet formation of silica loaded monomer}

Miniemulsions with different silica contents were prepared from a master batch of a relatively high concentrated dispersion of silica in monomer (35 wt \% silica relative to MMA/BA 50/50 by weight), which were diluted to the desired concentration of silica by adding monomer(s) prior to homogenization.

Stable miniemulsions were created by homogenization of silica-containing monomers in aqueous solution of surfactants using the set-up in Figure 1 and the recipes given in Table 2, using different amounts of silica varying from 0 to $20 \% \mathrm{w} / \mathrm{w}$ relative to total monomer. Droplet size is illustrated in Figure 4 as a function of homogenization time for different silica contents. As can be seen, droplet size decreases as a function of homogenization time as in the case of the unloaded dispersions shown in Figure 2. The results also show that droplet size increased with increasing silica content. At $20 \mathrm{wt} \%$ silica content droplet size is very close to that of $15 \mathrm{wt} \%$ silica content. This could be due to the fact that when silica content reaches to $15 \%$ the viscosity of dispersed phase is relatively high and the energy dissipated by SM might not be enough to break up the droplets as much as samples other samples with lower silica content. General forms of these curves are similar to those obtained for silica-free system; however the presence of silica particles slightly changes the behaviour of system. It worth mentioning that this phenomenon has 
reported in literature both for silica particles ${ }^{11}$ and titanium dioxide. ${ }^{12-14}$ The increasing monomer droplet size containing titanium dioxide has been contributed to the lower adsorption of surfactant on the droplets in the presence of hydrophobic titanium dioxide particles. ${ }^{13}$ We did not found any publications that discussing this topic in depth for silica particles.

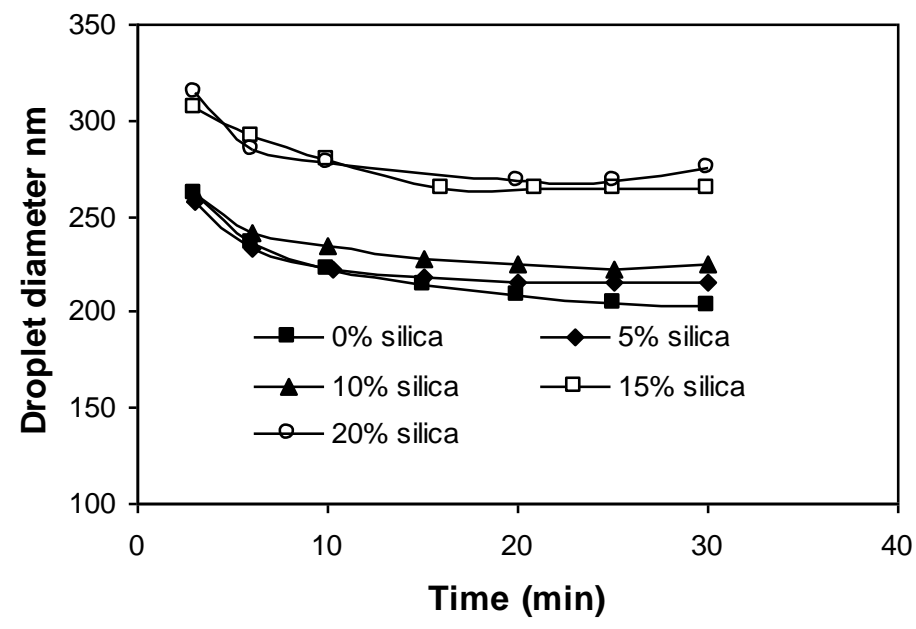

Figure 4. Evolution of droplet diameter versus homogenization time.

The evolution of the polydispersity index for miniemulsions as a function of silica content is plotted in Figure 5. As can be seen here it increases as the silica content is increased. This could be due to the distribution of silica particles in the droplets. Silica particles form a circular configuration at the interface of monomer/water and create some large droplets. This may increase the variance of droplet size in miniemulsion.

\section{Effect of the silica particles on polymerization}

The conversion of reaction for silica contents varying from 0 to $20 \%$ versus time is shown in Figure 6. There does not appear to be a not clear dependency of conversion on silica content. 


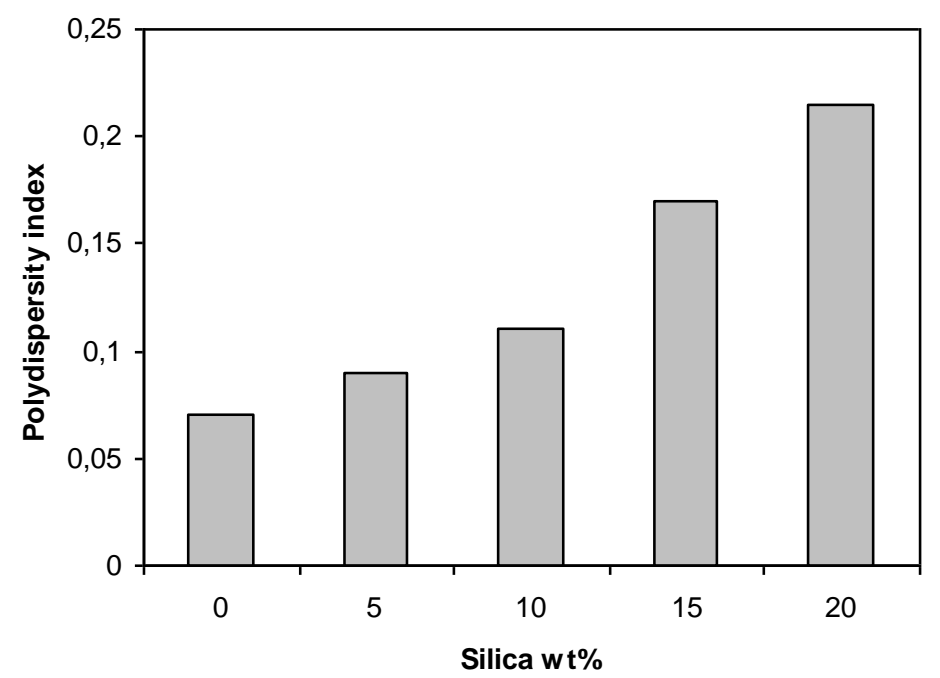

Figure 5. Evolution of polydispersity index as a function of silica content.

Figure 7 shows the evolution of particle diameter as a function of polymerization time. As can be seen from this figure, particle size decreases at the beginning of the polymerization and then slightly increases and reaches to a plateau. As stated previously this could be attributed to the homogeneous nucleation ${ }^{15}$ at the beginning of reaction and the coagulation of newly created particles (There might not be enough surfactant in the system). When the silica content reaches 15 wt \% the final average particle size is smaller than in cases with less than 15 wt $\%$ silica content. This suggests that a significant number of new particles created by secondary nucleation appear to be stabilized. Because the droplets are larger when silica content reaches to $15 \mathrm{wt} \%$, there is more free surfactant in aqueous phase. Creation of new particles during polymerization can be clearly seen from Figure 8 where we see the PI of miniemulsions as a function of time for different silica content. As can be seen, the PI decreases during polymerization and at the end of polymerization it is slightly higher than 0.1 for silica content higher than $10 \%$ and lower than this value for silica content less than $10 \%$. 


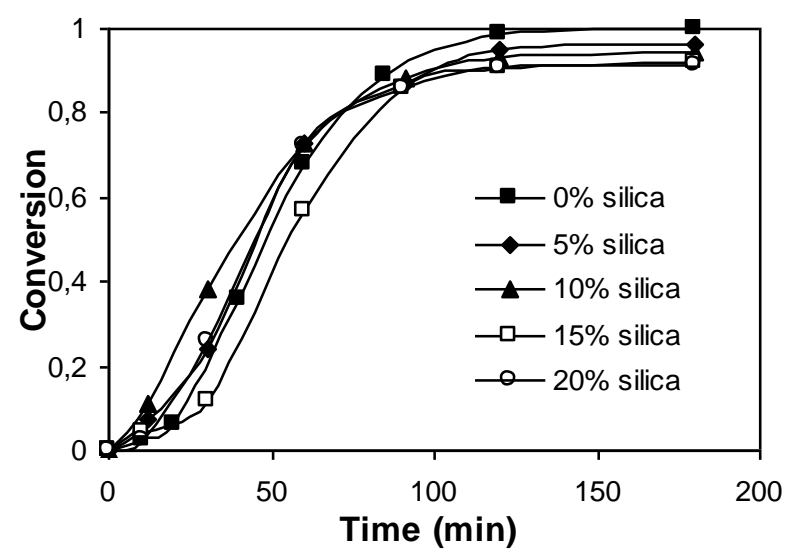

Figure 6. Conversion of polymerization for miniemulsion with different silica content

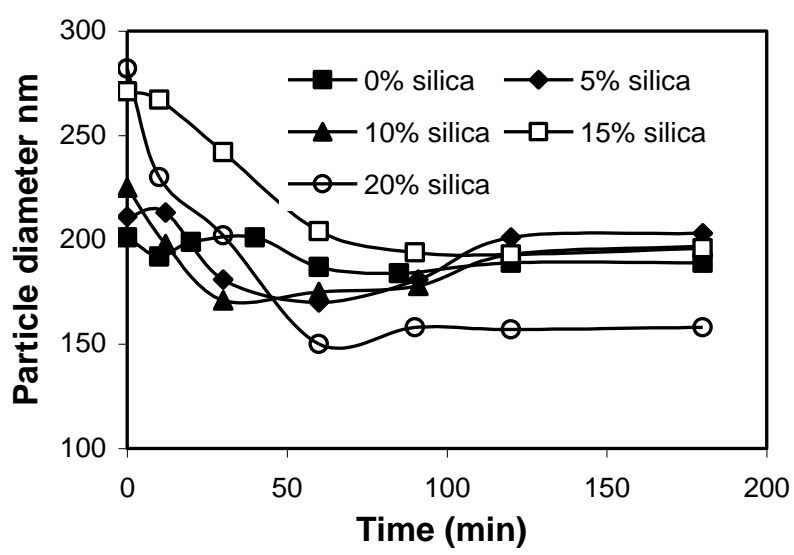

Figure 7. Evolution of particle diameter during polymerization

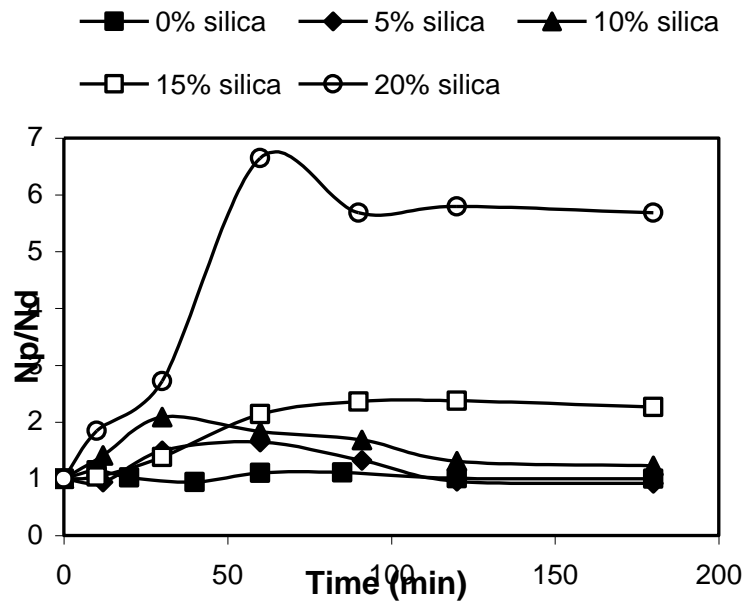

Figure 8. Monitoring of $\mathrm{Np} / \mathrm{Nd}$ during polymeization 


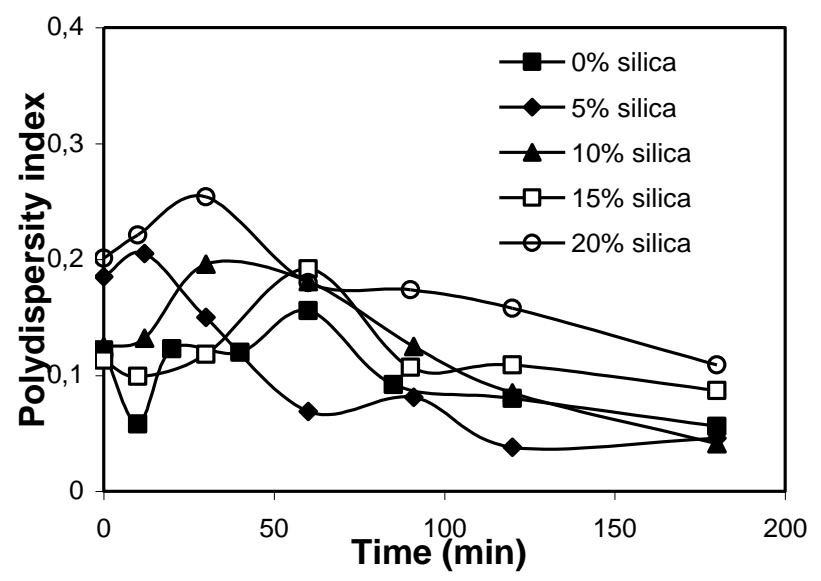

Figure 9. Variation of polydispersity during the polymerization

The variation of $\mathrm{N}_{\mathrm{p}} / \mathrm{N}_{\mathrm{d}}$ as function of PI is shown in Figure 10. It should be noted that when PI is close to 0.1 and the DSD of a miniemulsion is relatively narrow, $\mathrm{N}_{\mathrm{p}} / \mathrm{N}_{\mathrm{d}}$ remains closer to unity during and at the end of polymerization. This suggests that PI has an important effect on the nucleation step and a good droplet nucleation can be occurred if droplet size is small enough and DSD is narrow enough.

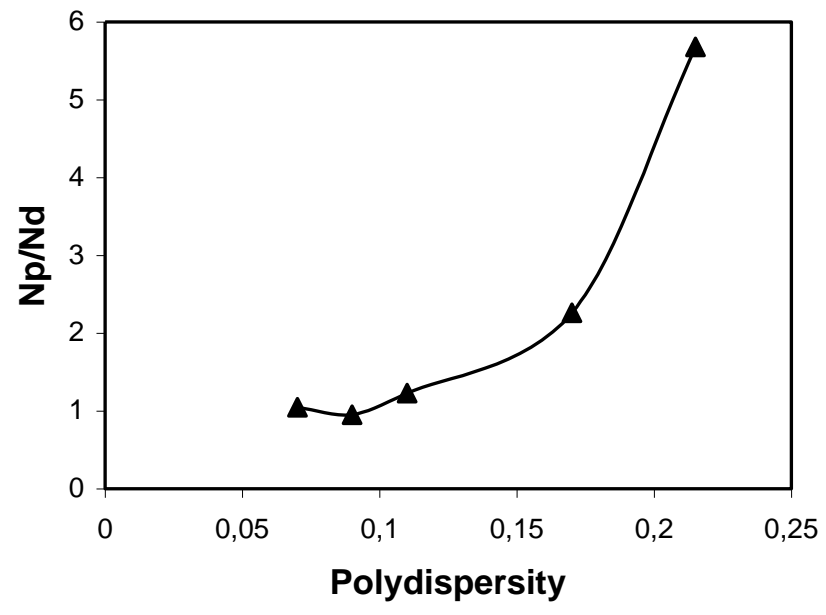

Figure 10. Effect of the polydispersity of miniemulsion on $\mathrm{Np} / \mathrm{Nd}$

\section{Conclusion}

A Sulzer SMX mixer set-up was successfully used as homogenization device for the miniemulsification of a mixture of monomers (MMA/BA 50/50 wt\%). Then the same homogenization system was used to disperse silica-loaded monomer. The resulting 
miniemulsions had narrow enough DSD to be successfully polymerized to prepare silica/polyacrylate composite nanoparticles. It was found that the droplet size depends on the silica content and increases with increasing the silica concentration. It was also shown that there is a relationship between the droplet size and the viscosity of the dispersed phase. The majority of droplets were nucleated upon polymerization when less than $15 \%$ silica was used. However, when the silica content exceeded $15 \%, \mathrm{~N}_{\mathrm{p}} / \mathrm{N}_{\mathrm{d}}$ increased to value much higher than 1 indicating the occurrence of homogeneous nucleation.

\section{References}

1. Ugelstad; El-Aasser, M. S.; Vanderhoff, J. W. Journal of Polymer Science 1973, 11, (8), 503-513.

2. Schork, F. J.; Luo, Y.; Smulders, W.; Russum, J. P.; Butte, A.; Fontenot, K. Advances in Polymer Science 2005, 175, (Polymer Particles), 129-255.

3. $\quad$ Landfester, K. Macromol. Rapid. Commun. 2001, 22, P896-936.

4. $\quad$ Antonietti, M.; Landfester, K. Progress in Polymer Science 2002, 27, (4), 689-757.

5. $\quad$ Asua, J. M. Progress in Polymer Science 2002, 27, (7), 1283-1346.

6. Ouzineb, K. Emulsion and miniemulsion polymerization: Stabilization, Turbular reactor and paractical application. Université de Lyon1, Lyon, 2003.

7. Ouzineb, K.; Lord, C.; Lesauze, N.; Graillat, C.; Tanguy, P. A.; McKenna, T. Chemical Engineering Science 2006, 61, (9), 2994-3000.

8. Farzi, G. A., Bourgeat-Lami, E., McKenna,T.F.L., . Journal of Applied Polymer Science 2009, in press.

9. Hansen, F. K.; Ugelstad, J. Journal of Polymer Science, Polymer Chemistry Edition 1978, $16,(8), 1953-79$.

10. Landfester, K.; Bechthold, N.; Förster, S.; Antonietti, M. Macromolecular rapid communications 1999, 20, (2), 81-84.

11. Qi, D.-m.; Bao, Y.-z.; Weng, Z.-X.; Huang, Z.-m. Polymer 2006, 47, (13), 4622-4629.

12. Erdem, B.; Sudol, E. D.; Dimonie, V. L.; El-Aasser, M. S. Journal of Polymer Science Part A: Polymer Chemistry 2000, 38, (24), 4419-4430.

13. Erdem, B.; Sudol, E. D.; Dimonie, V. L.; El-Aasser, M. S. Journal of Polymer Science Part A: Polymer Chemistry 2000, 38, (24), 4431-4440.

14. Erdem, B.; Sudol, E. D.; Dimonie, V. L.; El-Aasser, M. S. Journal of Polymer Science Part A: Polymer Chemistry 2000, 38, (24), 4441-4450.

15. Fitch, R. M. British polymer journal 1973, 5, (6), 467-483. 